Article

\title{
Synthesis of $\mathrm{Ge}_{1-x} \mathrm{Sn}_{x}$ Alloy Thin Films by Rapid Thermal Annealing of Sputtered Ge/Sn/Ge Layers on Si Substrates
}

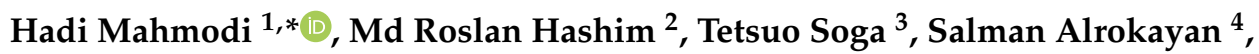 \\ Haseeb A. Khan ${ }^{4}$ (D) and Mohamad Rusop ${ }^{5}$ \\ 1 Nano-Optoelectronics Research Laboratory, School of Physics, Universiti Sains Malaysia, \\ 11800 USM Pulau Penang, Malaysia \\ 2 Institute of Nano-Optoelectronics Research and Technology Laboratory, Universiti Sains Malaysia, \\ Penang 11900, Malaysia; roslan@usm.my \\ 3 Department of Electrical and Mechanical Engineering, Nagoya Institute of Technology, Nagoya 466-8555, \\ Japan; soga.tetsuo@nitech.ac.jp \\ 4 Research Chair for Biomedical Applications of Nanomaterials, Biochemistry Department, College of Science, \\ King Saud University, Riyadh 11451, Saudi Arabia; salrokayan@ksu.edu.sa (S.A.); \\ haseeb@ksu.edu.sa (H.A.K.) \\ 5 NANO-SciTech Centre, Institute of Science, Universiti Teknologi MARA, Shah Alam, Selangor 40450, \\ Malaysia; nanouitm@gmail.com \\ * Correspondence: hadi.mahmodi@gmail.com; Tel.: +60-177-809-660
}

Received: 25 October 2018; Accepted: 7 November 2018; Published: 12 November 2018

\begin{abstract}
In this work, nanocrystalline $\mathrm{Ge}_{1-\mathrm{x}} \mathrm{Sn}_{\mathrm{x}}$ alloy formation from a rapid thermal annealed $\mathrm{Ge} / \mathrm{Sn} / \mathrm{Ge}$ multilayer has been presented. The multilayer was magnetron sputtered onto the Silicon substrate. This was followed by annealing the layers by rapid thermal annealing, at temperatures of $300{ }^{\circ} \mathrm{C}, 350{ }^{\circ} \mathrm{C}, 400{ }^{\circ} \mathrm{C}$, and $450{ }^{\circ} \mathrm{C}$, for $10 \mathrm{~s}$. Then, the effect of thermal annealing on the morphological, structural, and optical characteristics of the synthesized $\mathrm{Ge}_{1-\mathrm{x}} \mathrm{Sn}_{\mathrm{x}}$ alloys were investigated. The nanocrystalline $\mathrm{Ge}_{1-x} \mathrm{Sn}_{\mathrm{x}}$ formation was revealed by high-resolution X-ray diffraction (HR-XRD) measurements, which showed the orientation of (111). Raman results showed that phonon intensities of the Ge-Ge vibrations were improved with an increase in the annealing temperature. The results evidently showed that raising the annealing temperature led to improvements in the crystalline quality of the layers. It was demonstrated that Ge-Sn solid-phase mixing had occurred at a low temperature of $400{ }^{\circ} \mathrm{C}$, which led to the creation of a $\mathrm{Ge}_{1-x} \mathrm{Sn}_{\mathrm{x}}$ alloy. In addition, spectral photo-responsivity of a fabricated $\mathrm{Ge}_{1-x} \mathrm{Sn}_{\mathrm{x}}$ metal-semiconductor-metal (MSM) photodetector exhibited its extending wavelength into the near-infrared region $(820 \mathrm{~nm})$.
\end{abstract}

Keywords: semiconductors; thin films; Ge-Sn; nanocrystalline; sputtering; Raman spectroscopy; scanning electron microscopy; X-ray diffraction

\section{Introduction}

Silicon ( $\mathrm{Si}$ ) has been the dominant semiconductor material for about a few decades. The introduction of $\mathrm{Ge}_{1-x} \mathrm{Sn}_{\mathrm{x}}$ alloys [1] has extended the dominance of Si technology into areas previously dominated by III-V materials [2]. However, $\mathrm{Si}, \mathrm{Ge}$, and $\mathrm{Ge}_{1-} \mathrm{Si}_{\mathrm{x}}$ are indirect band-gap semiconductors and, therefore, cannot be used to fabricate laser, since it requires a direct band-gap material. Recently, $\mathrm{Ge}_{1-x} \mathrm{Sn}_{\mathrm{x}}$ alloy, as a group-IV alloy semiconductor, has received significant attention due to the potential possibilities for advanced optoelectronic devices, in future [3,4]. GeSn offers tunable direct band-gap when the Sn content is larger than about $6.5 \%-11 \%$ [5-7]. In addition, this 
alloy band gap can be tuned in the infrared range. In recent years, several types of optoelectronics and electronics devices such as laser [8], light emitting diodes (LEDs) [9], diodes [10], photoconductors [11], and p-i-n photodetectors [12] have been fabricated from GeSn film.

The low solubility of $\mathrm{Sn}$ and Ge (>1\%) [13], Sn surface segregation [14] and huge lattice mismatch between $\alpha$-Sn and Germanium [15] make the growing of epitaxial $\mathrm{Ge}_{1-x} \mathrm{Sn}_{\mathrm{x}}$ films difficult and introduce more challenges. However, non-equilibrium growth approaches have been developed for growing GeSn alloys; including molecular beam epitaxy (MBE) [16,17], chemical vapor deposition (CVD) [18-20], solid phase epitaxy (SPE) [21], pulsed laser deposition (PLD) [22], and magnetron sputtering $[12,23,24]$. Consequently, high-quality epitaxial $\mathrm{Ge}_{1-x} \mathrm{Sn}_{\mathrm{x}}$ alloy film have been grown by these techniques. Compared to the above-mentioned growth methods, magnetron sputtering provides some advantages, such as a low-cost technique, an independent and easily controlled growth rate and growth temperature, a simple control over the alloy composition, and most significantly, the Ge and Sn targets are much safer than the currently used precursor gas, in an MBE or CVD. In addition, these techniques require a precise substrate temperature control and very clean Si surface. Up till now, limited research has been carried out on the use of sputtering, to grow a GeSn alloy. Growing crystalline GeSn layers, by post-deposition annealing, has also not been well-studied. Through this technique, epitaxial GeSn films are formed by depositing an amorphous GeSn film on the Si or Ge substrate, followed by an annealing process. The driving force for the GeSn formation is the incorporation of the Sn into the Ge, through a solid-phase mixing. The post-deposition methods that have been used to crystalize GeSn alloy consist of a solid-phase epitaxy, thermal, and laser annealing. The solid phase crystallization temperature of GeSn is lower than those of the Ge and $\mathrm{Si}_{1-x} \mathrm{Ge}_{\mathrm{x}}$. The annealing temperature for $\mathrm{SiGe}$ annealing, using this technique, requires over $100{ }^{\circ} \mathrm{C}$ to mix the germanium and the silicon [25-27]. However, the employment of this technique for GeSn formation is desirable, due to its simple process and low cost.

In this study, the multilayers of Ge/Sn/Ge were sputtered onto Si substrates, from high purity targets. Then, the layers of the multilayer structure were rapid thermal annealed (RTA), at various temperatures, over a short duration. The findings of this research present the effect of thermal annealing on the morphological, structural, and optical characteristics of the synthesized GeSn alloy layers, on Si. It was observed that utilizing the higher annealing temperatures resulted in an improvement of the crystallinity and optical characteristics of the nanocrystalline layers. In this experiment, the Ge-Sn solid-phase mixing (inter-diffusion) was a main driving force for the GeSn alloy formation, through rapid thermal annealing.

\section{Materials and Methods}

Prior to the deposition process, the RCA (Radio Corporation of America) cleaning technique was used to clean the n-type $\mathrm{Si}(100)$ wafers. The multilayer structure was obtained by subsequent deposition of Ge and Sn layers, onto the Si substrate. The amorphous multilayer, Ge/Sn/Ge, were sputtered in a radio frequency (RF) magnetron sputtering system (Edwards A500). The background pressure of the chamber was $1.20 \times 10^{-5}$ mbar and high purity $\mathrm{Ar}(99.999 \%)$ was used as a sputtering gas. The diameter of Germanium (99.999\%) and the Tin (99.999\%) targets were $10 \mathrm{~cm}$ and were placed $10 \mathrm{~cm}$ beneath the sample holder. The magnetrons were placed in a planar configuration. The multilayer was sputtered at a Ge RF power of $100 \mathrm{~W}$ and Sn RF power of $15 \mathrm{~W}$, at room temperature (RT). After deposition, multilayers were rapid thermal annealed at $300^{\circ} \mathrm{C}, 350{ }^{\circ} \mathrm{C}, 400{ }^{\circ} \mathrm{C}$, and $450{ }^{\circ} \mathrm{C}$, for $10 \mathrm{~s}$, in the nitrogen ambient.

To fabricate a metal-semiconductor-meal photodetector (MSM PD), Nickel was deposited onto the GeSn thin films, via vacuum thermal evaporation, to make two interdigitated Schottky contacts, through a metal mask (fingers pattern). Schematic of the MSM photodetector is shown in Figure 1a. In addition, as shown in Figure $1 \mathrm{~b}$, each electrode had five fingers. The width and length of each finger were $230 \mu \mathrm{m}$ and $3.3 \mathrm{~mm}$, respectively. The spacing between each finger was $400 \mu \mathrm{m}$. The 
fabricated devices were annealed at $400{ }^{\circ} \mathrm{C}$, in the tube furnace, with nitrogen flowing for five minutes. The thickness of the metal contacts was about $200 \mathrm{~nm}$.

(a)

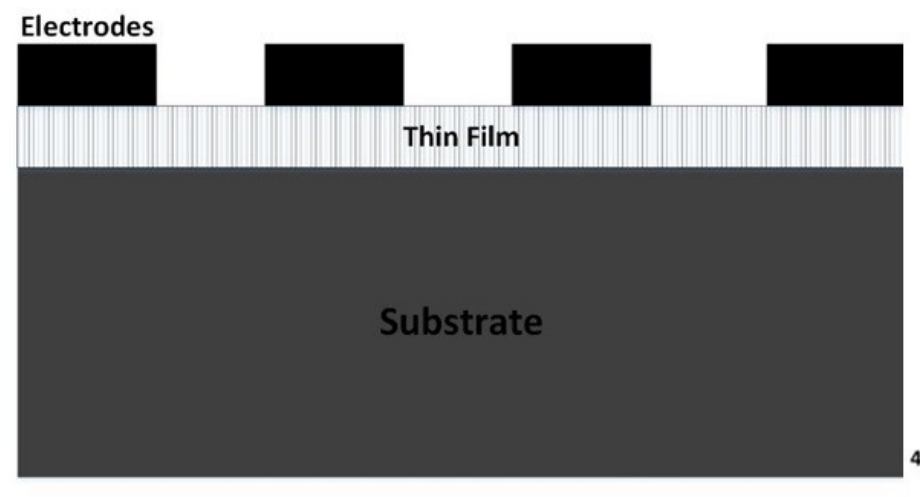

(b)

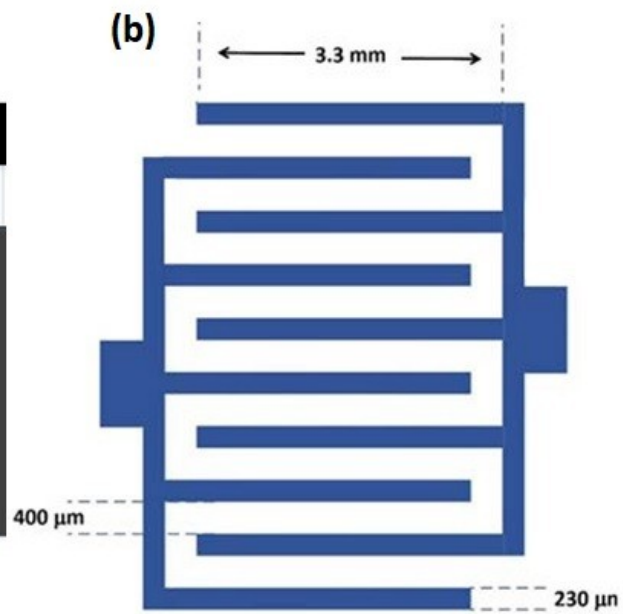

Figure 1. (a) Schematic of the metal-semiconductor-meal photodetector (MSM PD); and (b) schematic of the metal contact for the MSM PD fabrication.

The surface morphology of the samples was characterized via Field emission scanning electron microscopy (FESEM) (Nova NanoSEM 450, FEI, Netherlands). Energy-dispersive X-ray spectroscopy (EDX) was employed to recognize the elements existing in the films at $10 \mathrm{KV}$ acceleration voltage. Atomic force microscopy (AFM) (Dimension edge, Bruker, Billerica, MA, USA) was used to acquire AFM images, with a non-contact operation mode and a Nano Drive dimension-edge-tapping image-processing software (Version 6.13). Raman measurement was carried out with a Jobin-Yvon (HR800) spectrometer (Horiba, Longjumeau, France), where the thin films were excited at room temperature (RT) with an argon ion laser $(514.5 \mathrm{~nm}, 20 \mathrm{~mW})$. The crystallographic characterization of the layers was analyzed using a high-resolution X-ray diffractometer (HR-XRD) system (X'Pert3040) (Panalytical, Malvern, UK). The electrical measurements of the MSM photodetector were performed at RT, with a computer-controlled integrated SourceMeter Instrument (Model Keithley 2400, USA).

For the spectral responsivity measurement of the $\mathrm{Ge}_{1-x} \mathrm{Sn}_{\mathrm{x}} \mathrm{MSM} \mathrm{PD}$, the combination of a Xenon lamp and monochromator were used to generate the spectrum of light, with different wavelengths. The spectral responsivity of an optical detector is a measure of its electrical response to optical radiation, at a specified wavelength, which can be given as:

$$
\mathrm{R}=\frac{\mathrm{I}_{\text {photo }}-\mathrm{I}_{\text {dark }}}{\mathrm{E}}
$$

where $\mathrm{I}_{\text {photo }}$ is the photocurrent, $\mathrm{I}_{\text {dark }}$ is the dark current, and $\mathrm{E}$ is the incident optical power.

\section{Results and Discussion}

The HR-XRD spectra of the rapid thermal annealed multilayer of $\mathrm{Ge} / \mathrm{Sn} / \mathrm{Ge}$, at different temperatures, are shown in Figure 2. The sharp and intense peak detected at $2 \theta=69.32^{\circ}$ is attributed to the underlying $\mathrm{Si}(400)$ substrate. There are no diffraction patterns for the as-grown and annealed samples, at $300{ }^{\circ} \mathrm{C}$ (not shown). The XRD results of the annealed multilayer, at various annealing temperatures, are presented in Table 1. 


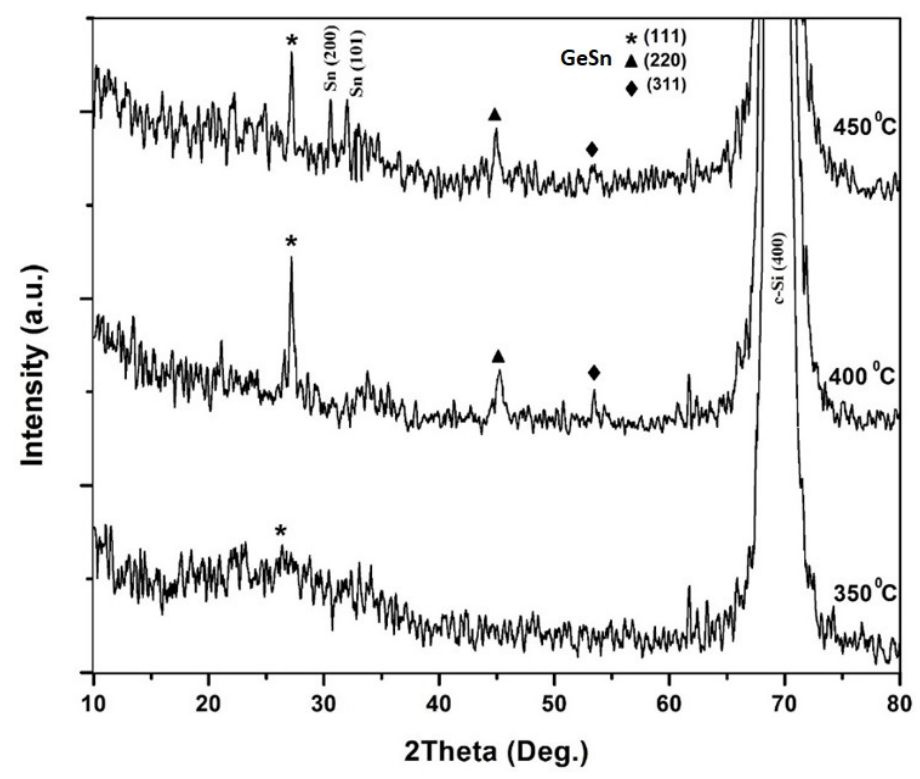

Figure 2. XRD pattern of the RTA samples at $350{ }^{\circ} \mathrm{C}, 400{ }^{\circ} \mathrm{C}$, and $450{ }^{\circ} \mathrm{C}$.

Table 1. XRD data for the annealed multilayer Ge/Sn/Ge samples at different temperatures.

\begin{tabular}{|c|c|c|c|c|c|}
\hline Sample & Orientation & $2 \theta$ (Deg.) & FWHM (Deg.) & Crystalline Size (nm) & Sn Composition (\%) \\
\hline \multirow{2}{*}{$400{ }^{\circ} \mathrm{C}$} & $(111)$ & 27.16 & 0.4208 & 20.30 & \multirow{2}{*}{2.7} \\
\hline & $(220)$ & 45.20 & 0.9012 & 9.97 & \\
\hline \multirow{2}{*}{$450^{\circ} \mathrm{C}$} & (111) & 27.22 & 0.3653 & 23.38 & \multirow{2}{*}{1.5} \\
\hline & $(220)$ & 45.25 & 0.5963 & 15.05 & \\
\hline
\end{tabular}

By raising the annealing temperatures over $400{ }^{\circ} \mathrm{C}$, a cubic (111) diffraction pattern became pronounced, which indicated the formation of $\mathrm{Ge}_{1-x} \mathrm{Sn}_{\mathrm{x}}$ alloy and an improvement in crystallinity of the annealed layers. This peak was between the $2 \theta$ angles of a-Sn (111) and c-Ge (111), 23.7 $27.3^{\circ}$, which is assigned to the cubic $\mathrm{Ge}_{1-x} \mathrm{Sn}_{\mathrm{x}}$ (111) structure [28]. The (111) diffraction pattern of the annealed sample at $450{ }^{\circ} \mathrm{C}$ had shifted to a higher angle, compared to the heated one at $400{ }^{\circ} \mathrm{C}$. The position of the peaks for the annealed layers, at temperatures of $400{ }^{\circ} \mathrm{C}$ and $450{ }^{\circ} \mathrm{C}$, were detected at the diffraction angles of $27.17^{\circ}$ and $27.22^{\circ}$, respectively.

Moreover, the observed peaks at $2 \theta=45.20^{\circ}$, and $2 \theta=45.25^{\circ}$, for the heated films at $400{ }^{\circ} \mathrm{C}$ and $450{ }^{\circ} \mathrm{C}$, respectively, belonged to the (220) orientation between the $2 \theta$ angles of $39.2^{\circ}$ (a-Sn) and $45.3^{\circ}$ (c-Ge). It was detected that increasing the annealing temperature led to a small shift to a higher $2 \theta$ angle, which was a result of a reduction of the layer's Sn content, upon heat treatment, as a result of the Sn surface segregation. Another low intensity diffraction pattern was observed at (311) orientation, between the $2 \theta$ angles of $39.2^{\circ}$ (a-Sn (311)) and $\sim 45.3^{\circ}$ (c-Ge (311)), as shown in Figure 2. It was clear that the (111) diffraction pattern was stronger than the (220) and (311) peaks. The (111) planes, in a diamond cubic structure, have the closest-packed arrangement. Therefore, these planes show the lowest surface/interface free energy [29]. Consequently, the presence of a sharp (111) plane is probable, as a result of its tendency to diminish the surface/interface free energy [30]. The two other observed peaks in the annealed layer, at $450{ }^{\circ} \mathrm{C}$, was attributed to Tin, because of surface segregation.

To estimate the average crystallite size from the full width half maximum (FWHM), Scherrer's formula [31] was used. For the annealed layer at $450{ }^{\circ} \mathrm{C}$, the crystallite size was higher than the one annealed at $400{ }^{\circ} \mathrm{C}$. The sample heated at $450{ }^{\circ} \mathrm{C}$ exhibited the largest crystallite size $(23 \mathrm{~nm})$. The high temperature annealing leads to an increase in the mobility of the individual atoms, over the crystallite surface [32], which leads to the formation of a larger crystallite size. The reduction of the FWHM of the peaks, upon post-deposition annealing, indicated an enhancement in the average crystallite size, and consequently, an enhancement in the crystallinity of the $\mathrm{Ge}_{1-x} \mathrm{Sn}_{x}$ alloy films. 
For estimating the $\mathrm{Sn}$ concentration in the annealed binary $\mathrm{Ge}_{1-x} \mathrm{Sn}_{\mathrm{x}}$ films, Vegard's law [33] was used for the $2 \theta$ angle of (111) diffraction (the shift in (220) peaks gives similar results):

$$
\mathrm{a}(\mathrm{x})=\mathrm{a}_{\mathrm{Ge}}(1-\mathrm{x})+\mathrm{a}_{\mathrm{Sn}} \mathrm{x}+\mathrm{b}_{\mathrm{GeSn}} \mathrm{x}(1-\mathrm{x})
$$

where $a$ is the lattice constant, $x$ is the $S n$ concentration, and $b_{G e S n}$ is the bowing parameter of GeSn $(b=0.041 \AA)$ [34]. As given in Table 1, the estimated Sn concentration from the XRD measurements were $2.7 \%, 1.5 \%$ for the sample annealed at $400{ }^{\circ} \mathrm{C}$ and $450{ }^{\circ} \mathrm{C}$, respectively. The annealed film at $450{ }^{\circ} \mathrm{C}$ showed lower $\mathrm{Sn}$ concentration, which suggested that a lesser amount of Sn dissolved in the $\mathrm{Ge}_{1-x} \mathrm{Sn}_{x}$ film. This was verified via the $2 \theta$ peak shifting to a higher angle. The synthesized $\mathrm{Ge}_{1-x} \mathrm{Sn}_{x}$ thin films became crystalline, at a low temperature of $400^{\circ} \mathrm{C}$, which was analogous to other research that had utilized RTA $[30,35]$. It was clear that the $\mathrm{Sn}$ incorporated in the $\mathrm{Ge}$, was higher than the $\mathrm{Sn}$ solid solubility in Ge.

Figure 3 displays the Raman spectra of all layers obtained at RT. Phonon peak position, intensity, FWHM, and peak shift for all layers are given in Table 2. The main sharp peak can be attributed to the Ge-Ge vibrations and the other, at $520.1 \mathrm{~cm}^{-1}$, belonged to the underlying Si wafer. The Ge-Sn peak was not observed. This was mainly due to the laser wavelength of $514.5 \mathrm{~nm}$, used in this study, which was far from the resonance condition with the $E_{1}-E_{1}+\Delta_{1}$ optical transitions $[36,37]$. The Ge-Sn bond was observed when the layer was excited by higher wavelengths; like $633 \mathrm{~nm}[38,39]$ and $647.1 \mathrm{~nm}[37]$. The Sn-Sn mode exhibited as a very low-intensity bump shape around $150 \mathrm{~cm}^{-1}$, as shown in Figure $3 \mathrm{~b}$.
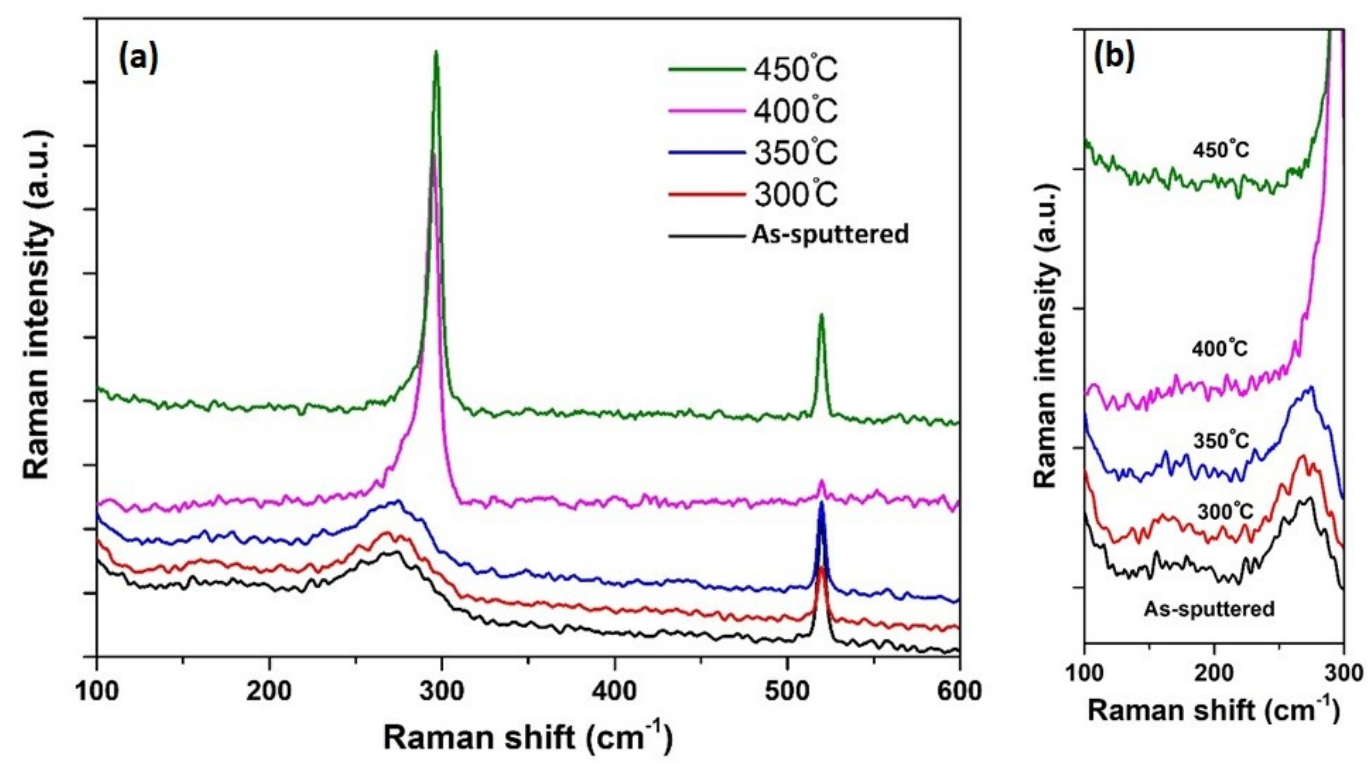

Figure 3. (a) Raman spectra of as-sputtered sample and annealed samples at $300{ }^{\circ} \mathrm{C}, 350{ }^{\circ} \mathrm{C}, 400{ }^{\circ} \mathrm{C}$, and $450{ }^{\circ} \mathrm{C}$. The spectra have been offset for clarity. (b) Sn-Sn mode of the samples.

Table 2. The details of the Ge-Ge mode of Raman spectra for the $\mathrm{Ge}_{1-x} \mathrm{Sn}_{\mathrm{x}}$ alloy films. The frequency shift value was compared to the as-sputtered sample.

\begin{tabular}{ccccccc}
\hline Samples & $\begin{array}{c}\text { Ge-Ge } \\
\left(\mathbf{c m}^{-1}\right)\end{array}$ & $\begin{array}{c}\text { Peak Intensity } \\
(\mathbf{a . u .})\end{array}$ & $\begin{array}{c}\text { FWHM } \\
\left(\mathbf{c m}^{-\mathbf{1}} \mathbf{)}\right.\end{array}$ & $\begin{array}{c}\text { Raman Shift } \\
\left(\mathbf{c m}^{\mathbf{1}}\right)\end{array}$ & $\begin{array}{c}\text { Raman } \\
\text { Shift }\left(\mathbf{c m}^{-\mathbf{1}} \mathbf{)}\right.\end{array}$ & $\mathbf{W}_{\mathbf{L}} / \mathbf{W}_{\mathbf{R}}$ \\
\hline As-grown & 276.32 & 661.00 & 45 & 24.71 & - & - \\
$300^{\circ} \mathrm{C}$ & 274.78 & 621.611 & 42 & 26.25 & - & - \\
$350^{\circ} \mathrm{C}$ & 274.62 & 659.833 & 35 & 26.41 & - & - \\
$400^{\circ} \mathrm{C}$ & 294.39 & 1773.83 & 12.76 & 6.64 & 18.07 & 3.231 \\
$450^{\circ} \mathrm{C}$ & 296.60 & 1719.00 & 8.29 & 4.43 & 20.28 & 1.274 \\
\hline
\end{tabular}

* Raman shift compared to the bulk Ge peak $\left(301.03 \mathrm{~cm}^{-1}\right)$. 
Applying the heat treatment to the sputtered films made significant changes on the peak and shape of the Raman spectra. Raman results exhibited significant changes in raising the treatment temperature to $400{ }^{\circ} \mathrm{C}$. As shown in Figure 3a, there was no significant changes in the Raman spectra of the layers annealed at $300{ }^{\circ} \mathrm{C}$ and $350{ }^{\circ} \mathrm{C}$, compared to the as-sputtered one. However, increasing the annealing temperatures to $400{ }^{\circ} \mathrm{C}$ and $450{ }^{\circ} \mathrm{C}$ made significant changes on the Ge-Ge mode peak intensity, FWHM, and the curve shapes. This was attributed to the Ge-Sn mixing to produce the $\mathrm{Ge}_{1-x} \mathrm{Sn}_{\mathrm{x}}$ alloy. Note that this crystallization temperature, at $400{ }^{\circ} \mathrm{C}$, was lower than the one for the polycrystalline $\mathrm{Ge}[40,41]$ and the $\mathrm{Si}_{1-x} \mathrm{Ge}_{x}$ [25-27].

The post-deposition annealing resulted in an increase in the intensity of the Ge-Ge phonon peak, as given in Figure 3a. The layers heated at a higher annealing temperature of $400{ }^{\circ} \mathrm{C}$ and $450{ }^{\circ} \mathrm{C}$, showed the highest phonon peak intensity, which showed intensities nearly three times higher than that of the as-deposited ones, indicating higher interactions with the incident photons, and consequently, an improvement in the crystalline structure of the $\mathrm{Ge}_{1-x} \mathrm{Sn}_{\mathrm{x}}$ alloy film produced.

In addition to phonon intensity variation, the Ge-Ge peak position had shifted upon the RTA process. This peak position for the as-grown and RTA samples, at $300{ }^{\circ} \mathrm{C}$ and $350{ }^{\circ} \mathrm{C}$, was located around $275 \mathrm{~cm}^{-1}$, which indicated their amorphous structure. In addition, the Ge-Ge peak in these samples belonged to the pure Ge layers, since no Ge-Sn intermixing had occurred. For the layers annealed at $400{ }^{\circ} \mathrm{C}$ and $450{ }^{\circ} \mathrm{C}$, the Ge-Ge peak had moved to a higher frequency, which had a shift of about $18.07 \mathrm{~cm}^{-1}$ and $20.28 \mathrm{~cm}^{-1}$, respectively, compared to the as-sputtered ones. In addition, the Ge-Ge peaks of all layers were downshifted and asymmetrically broadened towards the lower frequency side, with respect to the bulk Ge peak $\left(301.03 \mathrm{~cm}^{-1}\right)$. As given in Table 2, the FWHM of the Ge-Ge peak of the resulted $\mathrm{Ge}_{1-x} \mathrm{Sn}_{x}$ alloy had reduced with an annealing temperature increment, demonstrating an enhancement in the crystallinity of the heated layers, at high temperatures.

Figure 3 a shows the Ge-Ge peak broadening for the as-sputtered and the RTA samples, at $300{ }^{\circ} \mathrm{C}$ and $350^{\circ} \mathrm{C}$, which was due to compositional fluctuations in the alloy and the local disorder [42,43]. However, this broadening was decreased in the RTA annealed layers, at $400{ }^{\circ} \mathrm{C}$ and $500{ }^{\circ} \mathrm{C}$, by raising the annealing temperatures, indicating the presence of a nanocrystalline-phase with good crystallinity. Note that the bulk Ge was $\omega_{\mathrm{TO}}=301.3 \mathrm{~cm}^{-1}, \mathrm{FWHM} \approx 3.88 \mathrm{~cm}^{-1}$. As a result of the observed asymmetric Ge-Ge peak, the half-width at half-maximum (HWHM) were achieved for the RTA annealed samples, at $400{ }^{\circ} \mathrm{C}$ and $500{ }^{\circ} \mathrm{C}$, as mentioned in $[17,44]$. The Raman spectra displayed that the left low-energy side $\left(\mathrm{W}_{\mathrm{L}}\right)$ was clearly larger than the right high-energy side $\left(\mathrm{W}_{\mathrm{R}}\right)$. Table 2 shows that the ratio of the $\mathrm{W}_{\mathrm{L}} / \mathrm{W}_{\mathrm{R}}$ was slightly decreased by increasing the heating temperature, indicating a reduction in the asymmetry and an improvement in crystallinity. As mentioned in Reference [44], the value of $W_{L} / W_{R}$ has a direct correlation with the Tin content, as was also obtained in our research. The $W_{L} / W_{R}$ ratio was higher for the annealed sample at $400{ }^{\circ} \mathrm{C}$ and lower for the annealed sample at $450^{\circ} \mathrm{C}$. It has been proposed that the detected asymmetry and the phonon peak shifting were owing to the $\mathrm{Sn}$ addition to the Ge matrix.

Figure 4 shows the planar and cross-section views of the FE-SEM micrograph for the as-sputtered $\mathrm{Ge} / \mathrm{Sn} / \mathrm{Ge}$ multilayers on the Si substrate. In Figure 4a, the planar morphology of the as-grown sample displayed a densely-packed morphology. The surface contained large clusters, which resulted from the coalescence of small grains. Their range varied approximately from $15 \mathrm{~nm}$ to $50 \mathrm{~nm}$. Figure $4 \mathrm{~b}$ shows the cross-sectional view of the as-sputtered sample, which has clear interfaces between the Ge, $\mathrm{Sn}$, and the Si. The Sn layer was embedded between the two Ge layers. The thickness of the top and the bottom layers of the Ge and Sn layers were about $80 \mathrm{~nm}, 60 \mathrm{~nm}$, and $20 \mathrm{~nm}$, respectively. The total thickness of the multilayer was around $160 \mathrm{~nm}$ from the FE-SEM figure. 

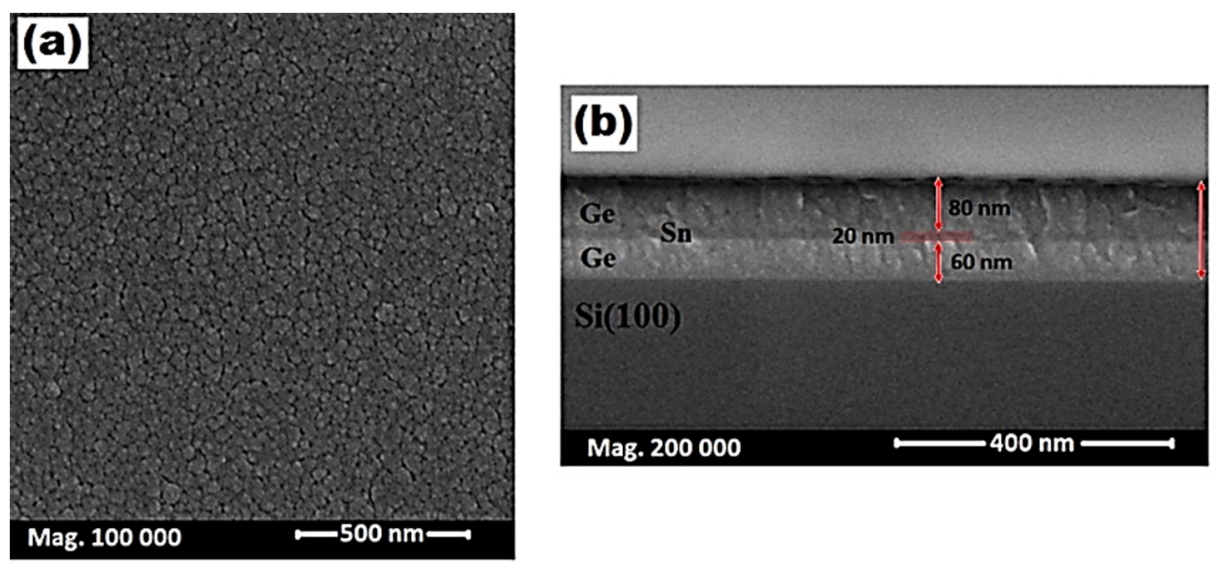

Figure 4. FE-SEM (a) planar and (b) cross-sectional views of the as-sputtered multilayer Ge/Sn/Ge structure.

Figure 5 displays the effect of the thermal annealing treatment on the multilayer Ge/Sn/Ge samples. FE-SEM images revealed quite significant changes in the surface morphology, upon RTA. However, the sample's surface preserved the densely-packed morphology, after the annealing process. The RTA at $300^{\circ} \mathrm{C}$ and $350^{\circ} \mathrm{C}$ caused the appearance of fracture or nano-cracks on the film's surface. From Figure $5 \mathrm{c}$ (the annealed sample at $400^{\circ} \mathrm{C}$ ), it is clear that the surface morphology had significantly changed, compared to the other low-temperature annealed samples. There was no sign of cracks on the surface of this sample, and the grains were slightly rounded. The film surface became more granular, with the lateral size ranging from a few tens of nanometers to about $80 \mathrm{~nm}$. It was clear that that the surface aggregation was smaller at RTA of $400{ }^{\circ} \mathrm{C}$. The reason was that the enhanced Sn atoms diffusion that was distributed on the coated flux on the layer surface, upon RTA, helped the growth of new grains and, therefore, produced a denser and finer film, which could be seen as round-shaped grains. It should be noted that the thermal expansion coefficient of Sn $\left(23 \times 10^{-6}\right)$ was much higher than Ge $\left(6.1 \times 10^{-6}\right)$ [45], which enhanced the solid-phase mixing. Increasing the annealing temperature, until $450{ }^{\circ} \mathrm{C}$, led to the creation of voids on the surface of the layer, which was attributed to a greater surface segregation of Tin. These findings demonstrated the important variations in the morphology of the samples, upon RTA.
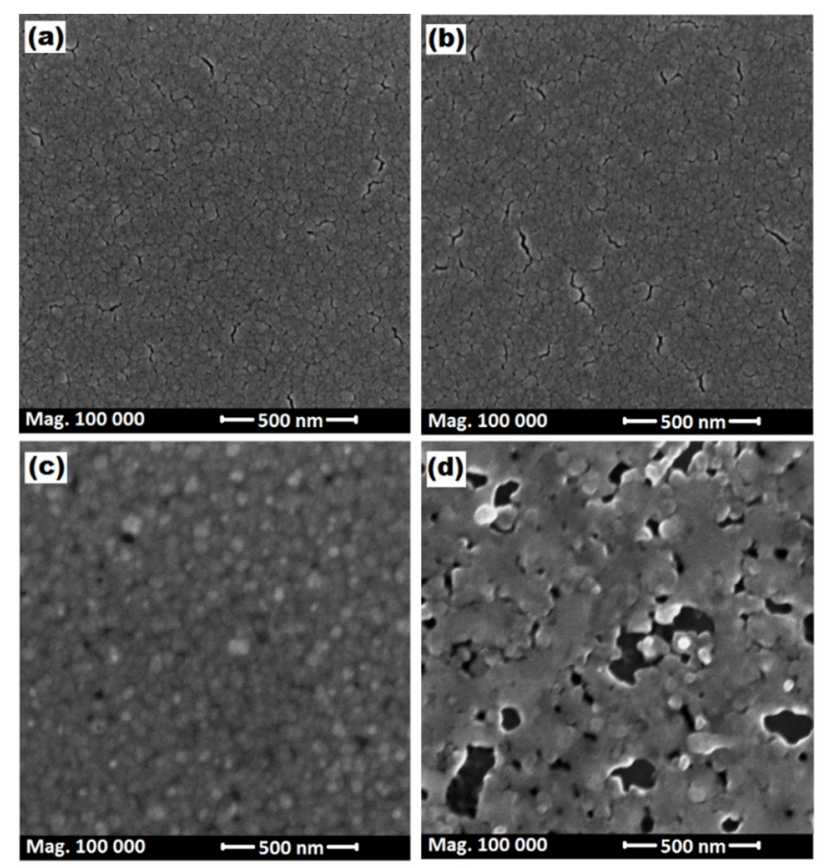

Figure 5. FE-SEM planar view of the RTA multilayer samples: (a) $300^{\circ} \mathrm{C}$; (b) $350{ }^{\circ} \mathrm{C}$; (c) $400{ }^{\circ} \mathrm{C}$; and (d) $450{ }^{\circ} \mathrm{C}$. 
The cross-sectional FESEM images of multilayer structures in Figure 6 exhibited well-defined and flat heterojunction interfaces and reveals a good adhesion to the $\mathrm{Si}$ substrate. The cross-sectional views also reveal the Ge-Sn inter-diffusion at the annealed temperature of $400{ }^{\circ} \mathrm{C}$ and $450{ }^{\circ} \mathrm{C}$. There is no sign of Ge and $\mathrm{Sn}$ layers and one single layer has been observed, which is attributed to $\mathrm{Ge}_{1-\mathrm{x}} \mathrm{Sn}_{\mathrm{x}}$ alloy film on Si substrate. While in the other samples, the Sn layer can be observed clearly. The appearance of these features indicated solid-phase mixing of $\mathrm{Ge}$ and $\mathrm{Sn}$ to form $\mathrm{Ge}_{1-\mathrm{x}} \mathrm{Sn}_{\mathrm{x}}$ alloy through inter-diffusion mechanism, which demonstrates that the incorporation of Tin into Germanium is needed to provoke the solid-phase mixing with the RTA temperature at least at $400{ }^{\circ} \mathrm{C}$ [45]. Note however, this crystallization temperature at $400^{\circ} \mathrm{C}$ is much lower than the one for pure $\mathrm{Ge}$, which is around $500{ }^{\circ} \mathrm{C}$ [46].
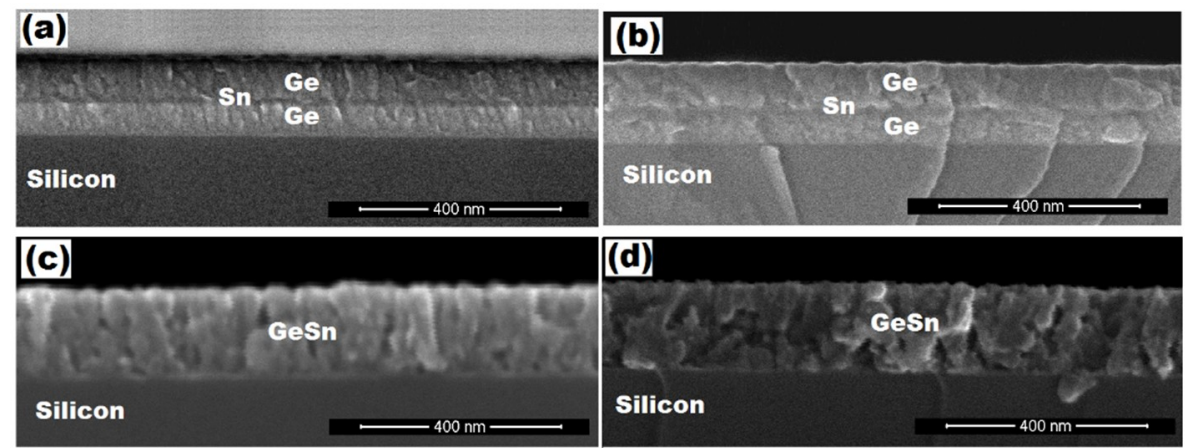

Figure 6. FE-SEM cross-sectional view of the rapid thermal annealed (RTA) multilayer samples: (a) $300{ }^{\circ} \mathrm{C}$; (b) $350{ }^{\circ} \mathrm{C}$; (c) $400{ }^{\circ} \mathrm{C}$; and (d) $450{ }^{\circ} \mathrm{C}$.

The three-dimensional AFM images of the as-deposited multilayer structure and the annealed layers in a scanned area of $5 \mu \mathrm{m} \times 5 \mu \mathrm{m}$ are shown in Figure 7 . The root mean square (RMS) surface roughness of the films is shown in Table 3. The RMS surface of the as-sputtered multilayer sample was $1.02 \mathrm{~nm}$. Significant changes were observed in the RTA annealed films at $400{ }^{\circ} \mathrm{C}$ and $450{ }^{\circ} \mathrm{C}$, in which the RMS surface increased to $1.77 \mathrm{~nm}$ and $2.85 \mathrm{~nm}$, respectively. The possible reason for this phenomenon was due to the solid-phase mixing (inter-diffusion) of the Ge and Sn atoms, in the multilayer structure [45], which caused the Sn surface segregation, and consequently the surface of thin films became rough, as was evident from the FE-SEM images.
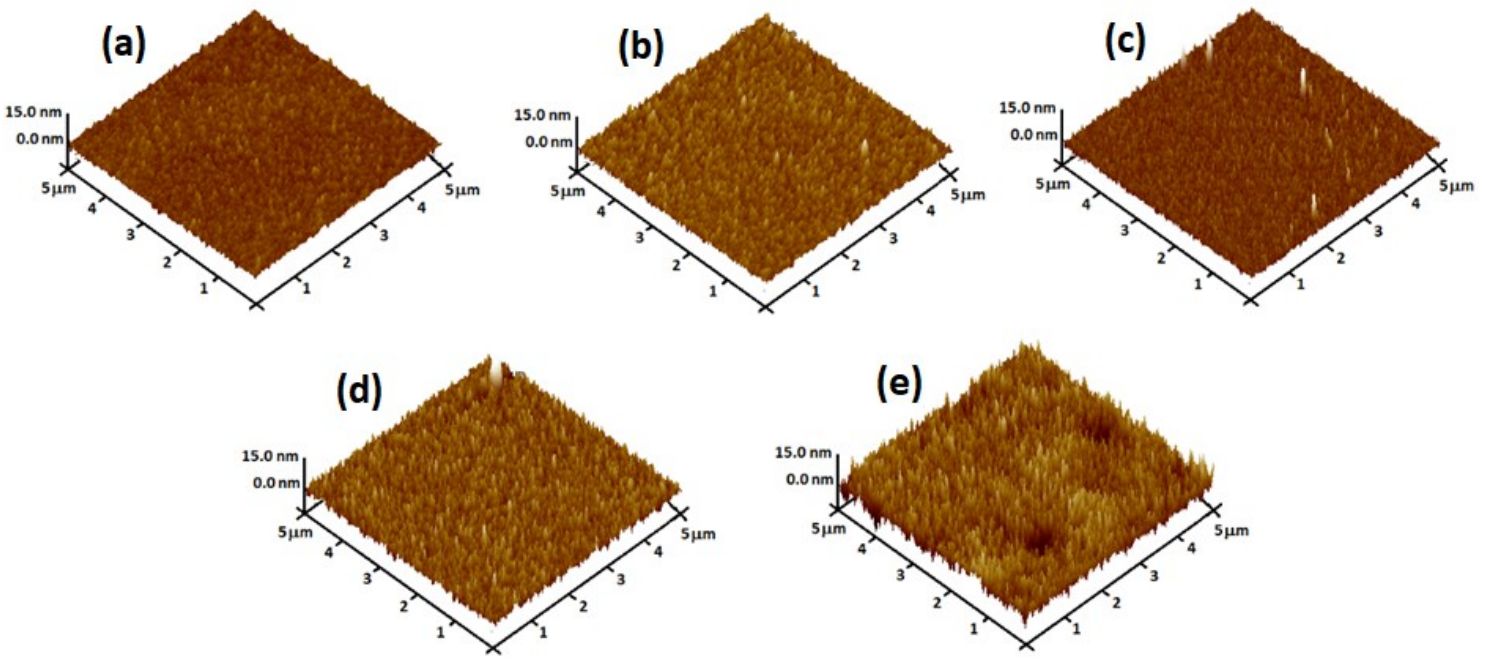

Figure 7. AFM images of GeSn thin films, (a) as-sputtered and annealed at (b) $300{ }^{\circ} \mathrm{C}$; (c) $350{ }^{\circ} \mathrm{C}$; (d) $400{ }^{\circ} \mathrm{C}$; and (e) $450{ }^{\circ} \mathrm{C}$. 
Table 3. Root mean square (RMS) surface roughness of the as-sputtered multilayer annealed structures and at different annealing temperatures.

\begin{tabular}{cccccc}
\hline Samples & As-Sputtered & $\mathbf{3 0 0}{ }^{\circ} \mathrm{C}$ & $\mathbf{3 5 0}{ }^{\circ} \mathrm{C}$ & $400{ }^{\circ} \mathrm{C}$ & $450{ }^{\circ} \mathrm{C}$ \\
\hline Surface Roughness $(\mathrm{nm})$ & 1.02 & 1.18 & 1.2 & 1.77 & 2.85 \\
\hline
\end{tabular}

The current-voltage (I-V) characteristics of the MSM PD on the RTA annealed film, at $400{ }^{\circ} \mathrm{C}$, is shown in Figure 8, under dark and visible light illumination. The inset shows the current gain.

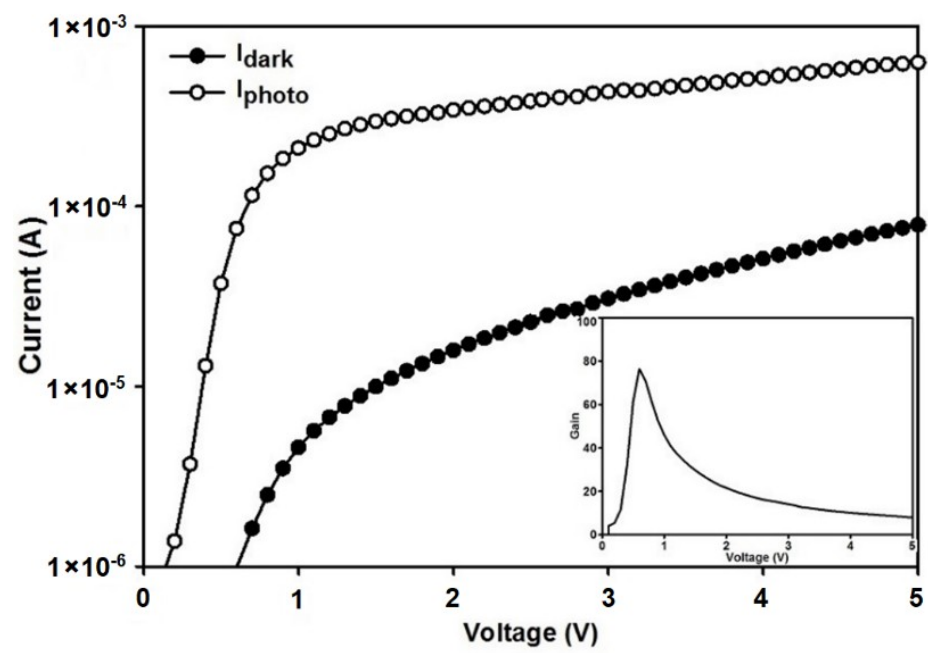

Figure 8. Current-voltage characteristics of the MSM PD on the RTA annealed sample, at $400{ }^{\circ} \mathrm{C}$, measured in the dark $\left(\mathrm{I}_{\text {dark }}\right)$, and under illumination $\left(\mathrm{I}_{\text {Photo }}\right)$. The inset shows the current gain $\left(\mathrm{I}_{\text {photo }} / \mathrm{I}_{\text {dark }}\right)$.

The response of a $\mathrm{Ge}_{1-x} \mathrm{Sn}_{x}$ MSM PD increased with the bias voltage and saturated gradually at a voltage above $1.0 \mathrm{~V}$, which was due to the movement of all carriers, toward the PD electrodes. It was obvious that the photocurrent produced a higher current than that of the dark, due to the photo-generation current, upon light illumination. Comparing the current at $5 \mathrm{~V}$ bias, the photocurrent was $5.39 \times 10^{-4} \mathrm{~A}$, while the dark one was $7.21 \times 10^{-5} \mathrm{~A}$. In addition, the current gain of this RTA sample exhibited a value of about 80 , at $0.8 \mathrm{~V}$ bias, which indicated its higher sensitivity to the incident illumination. Meanwhile, this indicated a high photo-responsivity of the RTA $\mathrm{Ge}_{1-\mathrm{x}} \mathrm{Sn}_{\mathrm{x}}$ film. The higher current gain at this low voltage could be due to the increase of the surface resistivity. As shown in the AFM image, the RMS surface roughness of this sample $\left(400{ }^{\circ} \mathrm{C}\right)$ was $1.77 \mathrm{~nm}$, which was higher, compared to the as-sputtered one and moreover some small holes were observed in the FE-SEM image (Figure 5c), due to the Sn surface segregation. Therefore, this slightly high surface roughness, enhanced the resistivity of this sample and, thus, decreased the dark current value. In addition, the spectral photo-response measurement had been performed on the optimized MSM PD sample, which went through RTA at $400{ }^{\circ} \mathrm{C}$. Figure 9 illustrates the responsivity for the $\mathrm{Ge}_{0.973} \mathrm{Sn}_{0.027}$ MSM PD versus the wavelength, which was measured at RT. The investigated wavelength area was from $500 \mathrm{~nm}$ to $1000 \mathrm{~nm}$. The photocurrent value was measured at a fixed voltage of $5 \mathrm{~V}$. It was clearly observed that the responsivity dropped around the $820 \mathrm{~nm}$. The measured responsivity at this wavelength was $\sim 0.17 \mathrm{~A} / \mathrm{W}$. Due to the alloy broadening, the absorption edge was not as steep as that of the pure material. 


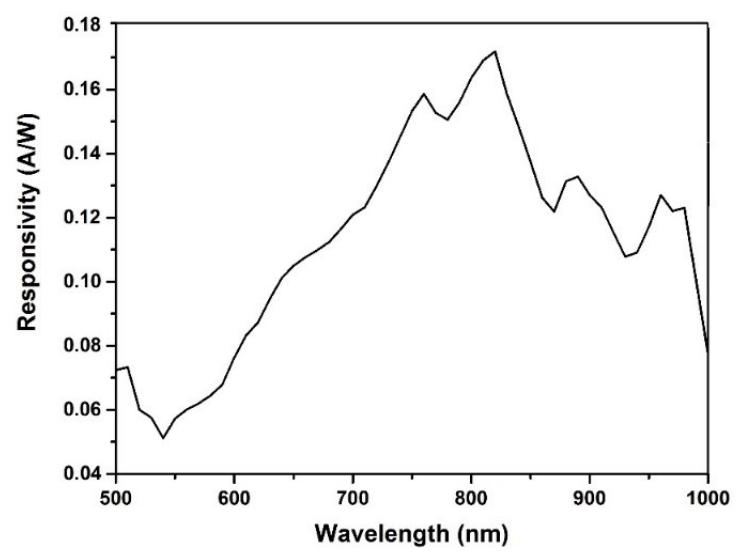

Figure 9. The photo-response of the $\mathrm{Ge}_{0.973} \mathrm{Sn}_{0.027} \mathrm{MSM}$ PD.

\section{Conclusions}

The nanocrystalline $\mathrm{Ge}_{1-\mathrm{x}} \mathrm{Sn}_{\mathrm{x}}$ alloy were successfully grown on the $\mathrm{Si}$ substrate, via $\mathrm{Ge} / \mathrm{Sn} / \mathrm{Ge}$ multilayer magnetron sputtering, after rapid thermal annealing. The Raman analysis exhibited an enhancement in the intensities of the Ge-Ge peak, upon RTA at $400{ }^{\circ} \mathrm{C}$, and above. The XRD results demonstrated that the Ge-Sn solid-phase mixing had occurred at a low temperature of $400{ }^{\circ} \mathrm{C}$, which led to the creation of the $\mathrm{Ge}_{1-x} \mathrm{Sn}_{x}$ alloy. The crystallinity of the $\mathrm{Ge}_{1-x} \mathrm{Sn}_{x}$ thin films improved expressively in the (111) orientation. RTA at $400{ }^{\circ} \mathrm{C}$ resulted in a uniform GeSn layer, with enhanced optical characteristics. The fabricated $\mathrm{Ge}_{1-x} \mathrm{Sn}_{\mathrm{x}}$ MSM PD exhibited its photosensitivity at $820 \mathrm{~nm}$. The obtained results exposed the potentiality of using the sputtering technique and the RTA to produce crystalline $\mathrm{Ge}_{1-\mathrm{x}} \mathrm{Sn}_{\mathrm{x}}$ material on the $\mathrm{Si}$ substrate, for photonic and light-sensing device applications.

Author Contributions: Conceptualization, H.M. and M.R.; Methodology, H.M.; Validation, M.R. and T.S.; Formal analysis, H.M and S.A.; Investigation, H.M; Resources, H.M., M.R.H.; Data curation, H.M. and S.A.; writing-original draft preparation, H.M.; Supervision, M.R.H.; writing-review and editing, M.A., H.A.K. and T.S.

Funding: This research was funded by Universiti Sains Malaysia grant number 1001/PFIZIK/846072. This study was partly funded by Deanship of Scientific Research, King Saud University by their support through Vice Deanship of Scientific Research Chairs.

Acknowledgments: The authors are grateful to Institute of Research Management and Innovation (Universiti Teknologi MARA), Department of Electrical and Mechanical Engineering (Nagoya Institute of Technology), and the Deanship of Scientific Research (King Saud University) for their support through Vice Deanship of Scientific Research Chairs.

Conflicts of Interest: The authors declare no conflict of interest.

\section{References}

1. Fan, Q.; Chai, C.; Wei, Q.; Zhou, P.; Yang, Y. Two novel Ge phases and their SiGe alloys with excellent electronic and optical properties. Mater. Des. 2017, 132, 539-551. [CrossRef]

2. Douglas, J.P. Si/SiGe heterostructures: From material and physics to devices and circuits. Semicond. Sci. Technol. 2004, 19, R75.

3. Alberi, K.; Blacksberg, J.; Bell, L.D.; Nikzad, S.; Yu, K.M.; Dubon, O.D.; Walukiewicz, W. Band anticrossing in highly mismatched $\mathrm{Sn}_{\mathrm{x}} \mathrm{Ge}_{1-\mathrm{x}}$ semiconducting alloys. Phys. Rev. B 2008, 77, 073202. [CrossRef]

4. Yin, W.-J.; Gong, X.-G.; Wei, S.-H. Origin of the unusually large band-gap bowing and the breakdown of the band-edge distribution rule in the $\mathrm{Sn}_{\mathrm{x}} \mathrm{Ge}_{1-\mathrm{x}}$ alloys. Phys. Rev. B 2008, 78, 161203. [CrossRef]

5. D'Costa, V.R.; Cook, C.S.; Birdwell, A.G.; Littler, C.L.; Canonico, M.; Zollner, S.; Kouvetakis, J.; Menéndez, J. Optical critical points of thin-film $\mathrm{G}_{1-\mathrm{y}} \mathrm{Sn}_{\mathrm{y}}$ alloys: A comparative $\mathrm{G}_{1-\mathrm{y}} \mathrm{Sn}_{\mathrm{y}} / \mathrm{Ge}_{1-\mathrm{x}} \mathrm{Si}_{\mathrm{x}}$ study. Phys. Rev. B 2006, 73, 125207. [CrossRef]

6. Chen, R.; Lin, H.; Huo, Y.; Hitzman, C.; Kamins, T.I.; Harris, J.S. Increased photoluminescence of strain-reduced, high-Sn composition $\mathrm{Ge}_{1-\mathrm{x}} \mathrm{Sn}_{\mathrm{x}}$ alloys grown by molecular beam epitaxy. Appl. Phys. Lett. 2011, 99, 181125. [CrossRef] 
7. Gallagher, J.D.; Senaratne, C.L.; Kouvetakis, J.; Menéndez, J. Compositional dependence of the bowing parameter for the direct and indirect band gaps in $\mathrm{Ge}_{1-\mathrm{y}} \mathrm{Sn}_{\mathrm{y}}$ alloys. Appl. Phys. Lett. 2014, 105, 142102. [CrossRef]

8. Wirths, S.; Geiger, R.; von den Driesch, N.; Mussler, G.; Stoica, T.; Mantl, S.; Ikonic, Z.; Luysberg, M.; Chiussi, S.; Hartmann, J.M.; et al. Lasing in direct-bandgap GeSn alloy grown on Si. Nat. Photonics 2015, 9, 88-92. [CrossRef]

9. Du, W.; Hou, Z.; Ghetmiri, S.A.; Mosleh, A.; Conley, B.R.; Nazzal, A.; Soref, R.A.; Sun, G.; Tolle, J.; Margetis, J.; et al. Room-temperature electroluminescence from $\mathrm{Ge} / \mathrm{Ge}_{1-\mathrm{x}} \mathrm{Sn}_{\mathrm{x}} / \mathrm{Ge}$ diodes on Si substrates. Appl. Phys. Lett. 2014, 104, 241110. [CrossRef]

10. Baert, B.; Gupta, S.; Gencarelli, F.; Loo, R.; Simoen, E.; Nguyen, N.D. Electrical characterization of $\mathrm{p}-\mathrm{GeSn} / \mathrm{n}$-Ge diodes with interface traps under DC and AC regimes. Solid-State Electron. 2015, 110, 65-70. [CrossRef]

11. Conley, B.R.; Mosleh, A.; Ghetmiri, S.A.; Du, W.; Soref, R.A.; Sun, G.; Margetis, J.; Tolle, J.; Naseem, H.A.; $\mathrm{Yu}, \mathrm{S}$.-Q. Temperature dependent spectral response and detectivity of GeSn photoconductors on silicon for short wave infrared detection. Opt. Express 2014, 22, 15639-15652. [CrossRef] [PubMed]

12. Zheng, J.; Wang, S.; Liu, Z.; Cong, H.; Xue, C.; Li, C.; Zuo, Y.; Cheng, B.; Wang, Q. GeSn p-i-n photodetectors with GeSn layer grown by magnetron sputtering epitaxy. Appl. Phys. Lett. 2016, 108, 033503. [CrossRef]

13. Thurmond, C.D.; Trumbore, F.A.; Kowalchik, M. Germanium solidus curves. J. Chem. Phys. 1956, 25, 799-800. [CrossRef]

14. Pukite, P.R.; Harwit, A.; Iyer, S.S. Molecular beam epitaxy of metastable, diamond structure $\mathrm{Sn}_{\mathrm{x}} \mathrm{Ge}_{1-\mathrm{x}}$ alloys. Appl. Phys. Lett. 1989, 54, 2142-2144. [CrossRef]

15. Wang, W.; Su, S.; Zheng, J.; Zhang, G.; Xue, C.; Zuo, Y.; Cheng, B.; Wang, Q. Flattening of low temperature epitaxial $\mathrm{Ge}_{1-x} \mathrm{Sn}_{x} / \mathrm{Ge} / \mathrm{Si}(100)$ alloys via mass transport during post-growth annealing. Appl. Surf. Sci. 2011, 257, 4468-4471. [CrossRef]

16. Nikolenko, A.S.; Strelchuk, V.V.; Safriuk, N.V.; Kryvyi, S.B.; Kladko, V.P.; Oberemok, O.S.; Borkovska, L.V.; Sadofyev, Y.G. Structural and optical studies of strain relaxation in $\mathrm{Ge}_{1-x} \mathrm{Sn}_{\mathrm{x}}$ layers grown on $\mathrm{Ge} / \mathrm{Si}(001)$ by molecular beam epitaxy. Thin Solid Films 2015, 613, 68-74. [CrossRef]

17. Han, D.; Ye, H.; Song, Y.; Zhu, Z.; Yang, Y.; Yu, Z.; Liu, Y.; Wang, S.; Di, Z. Analysis of Raman scattering from inclined GeSn/Ge dual-nanowire heterostructure on Ge(111) substrate. Appl. Surf. Sci. 2019, 463, 581-586. [CrossRef]

18. Gencarelli, F.; Shimura, Y.; Kumar, A.; Vincent, B.; Moussa, A.; Vanhaeren, D.; Richard, O.; Bender, H.; Vandervorst, W.; Caymax, M.; et al. Amorphous inclusions during Ge and GeSn epitaxial growth via chemical vapor deposition. Thin Solid Films 2015, 590, 163-169. [CrossRef]

19. Dufrêne, Y.F.; Rouxhet, P.G. X-ray photoelectron spectroscopy analysis of the surface composition of Azospirillum brasilense in relation to growth conditions. Colloids Surf. B Biointerfaces 1996, 7, 271-279. [CrossRef]

20. Tsai, C.-E.; Lu, F.-L.; Chen, P.-S.; Liu, C.W. Boron-doping induced Sn loss in GeSn alloys grown by chemical vapor deposition. Thin Solid Films 2018, 660, 263-266. [CrossRef]

21. Lieten, R.R.; Seo, J.W.; Decoster, S.; Vantomme, A.; Peters, S.; Bustillo, K.C.; Haller, E.E.; Menghini, M.; Locquet, J.P. Tensile strained GeSn on Si by solid phase epitaxy. Appl. Phys. Lett. 2013, 102, 052106. [CrossRef]

22. Huang, Z.-M.; Huang, W.-Q.; Liu, S.-R.; Dong, T.-G.; Wang, G.; Wu, X.-K.; Qin, C.-J. Emission of direct-gap band in germanium with Ge-GeSn layers on one-dimensional structure. Sci. Rep. 2016, 6, 24802. [CrossRef] [PubMed]

23. Wang, Y.; Zhang, L.; Huang, Z.; Li, C.; Chen, S.; Huang, W.; Xu, J.; Wang, J. Crystallization of GeSn thin films deposited on $\mathrm{Ge}(100)$ substrate by magnetron sputtering. Mater. Sci. Semicond. Process. 2018, 88, $28-34$. [CrossRef]

24. Zheng, J.; Liu, Z.; Zhang, Y.; Zuo, Y.; Li, C.; Xue, C.; Cheng, B.; Wang, Q. Growth of high-Sn content (28\%) GeSn alloy films by sputtering epitaxy. J. Cryst. Growth 2018, 492, 29-34. [CrossRef]

25. Taoka, N.; Sakai, A.; Mochizuki, S.; Nakatsuka, O.; Ogawa, M.; Zaima, S. Control of misfit dislocations in strain-relaxed SiGe buffer layers on SOI substrates. Thin Solid Films 2006, 508, 147-151. [CrossRef]

26. Takayoshi, S.; Shimpei, O.; Chiaki, Y.; Takuji, H.; Heiji, W. Fabrication of fully relaxed SiGe layers with high Ge concentration on silicon-on-insulator wafers by rapid melt growth. Appl. Phys. Express 2010, 3, 105501. 
27. Nakaharai, S.; Tezuka, T.; Sugiyama, N.; Moriyama, Y.; Takagi, S.I. Characterization of 7-nm-thick strained Ge-on-insulator layer fabricated by Ge-condensation technique. Appl. Phys. Lett. 2003, 83, 3516-3518. [CrossRef]

28. Hirofumi, F.; Hiroaki, M.; Toshio, N.; Takeshi, I.; Yukio, O. Structural changes of amorphous Ge ${ }_{1-\mathrm{x}} \mathrm{Sn}_{\mathrm{x}}$ alloy films by annealing. Jpn. J. Appl. Phys. 1986, 25, 1312.

29. Castain, J. Hand Book of X-ray Photoelectron Spectroscopy; Perkin-Elmer Corp.: Minnisota, MN, USA, 1992.

30. Li, H.; Brouillet, J.; Salas, A.; Wang, X.; Liu, J. Low temperature growth of high crystallinity GeSn on amorphous layers for advancedoptoelectronics. Opt. Mater. Express 2013, 3, 1385-1396. [CrossRef]

31. Ramadoss, A.; Krishnamoorthy, K.; Kim, S.J. Facile synthesis of hafnium oxide nanoparticles via precipitation method. Mater. Lett. 2012, 75, 215-217. [CrossRef]

32. Yoichi, K.; Takaaki, S.; Shinji, K. Temperature dependence of mobility in silicon (100) inversion layers at low temperatures. Surf. Sci. 1982, 113, 218-222. [CrossRef]

33. Vegard, L. Die Konstitution der Mischkristalle und die Raumfüllung der Atome. Z. Phys. 1921, 5, 17-26. [CrossRef]

34. Gencarelli, F.; Vincent, B.; Demeulemeester, J.; Vantomme, A.; Moussa, A.; Franquet, A.; Kumar, A.; Bender, H.; Meersschaut, J.; Vandervorst, W.; et al. Crystalline properties and strain relaxation mechanism of CVD grown GeSn. ECS Trans. 2013, 50, 875-883. [CrossRef]

35. Conley, B.R.; Mosleh, A.; Ghetmiri, S.A.; Du, W.; Sun, G.; Soref, R.; Margetis, J.; Tolle, J.; Naseem, H.A.; $\mathrm{Yu}, \mathrm{S}$.-Q. Stability of pseudomorphic and compressively strained $\mathrm{Ge}_{1-\mathrm{x}} \mathrm{Sn}_{\mathrm{x}}$ thin films under rapid thermal annealing. ECS Trans. 2014, 64, 881-893. [CrossRef]

36. D'Costa, V.R.; Tolle, J.; Poweleit, C.D.; Kouvetakis, J.; Menéndez, J. Compositional dependence of Raman frequencies in ternary $\mathrm{Ge}_{1-\mathrm{x}-\mathrm{y}} \mathrm{Si}_{\mathrm{x}} \mathrm{Sn}_{\mathrm{y}}$ alloys. Phys. Rev. B 2007, 76, 035211. [CrossRef]

37. D'Costa, V.R.; Tolle, J.; Roucka, R.; Poweleit, C.D.; Kouvetakis, J.; Menéndez, J. Raman scattering in $\mathrm{Ge}_{1-\mathrm{y}} \mathrm{Sn}_{\mathrm{y}}$ alloys. Solid State Commun. 2007, 144, 240-244. [CrossRef]

38. Oehme, M.; Buca, D.; Kostecki, K.; Wirths, S.; Holländer, B.; Kasper, E.; Schulze, J. Epitaxial growth of highly compressively strained GeSn alloys up to $12.5 \%$ Sn. J. Cryst. Growth 2013, 384, 71-76. [CrossRef]

39. Fournier-Lupien, J.-H.; Mukherjee, S.; Wirths, S.; Pippel, E.; Hayazawa, N.; Mussler, G.; Hartmann, J.M.; Desjardins, P.; Buca, D.; Moutanabbir, O. Strain and composition effects on Raman vibrational modes of silicon-germanium-tin ternary alloys. Appl. Phys. Lett. 2013, 103, 263103. [CrossRef]

40. Tsao, C.-Y.; Weber, J.W.; Campbell, P.; Conibeer, G.; Song, D.; Green, M.A. In situ low temperature growth of poly-crystalline germanium thin film on glass by RF magnetron sputtering. Sol. Energy Mater. Sol. Cells 2010, 94, 1501-1505. [CrossRef]

41. Tsao, C.-Y.; Weber, J.W.; Campbell, P.; Widenborg, P.I.; Song, D.; Green, M.A. Low-temperature growth of polycrystalline Ge thin film on glass by in situ deposition and ex situ solid-phase crystallization for photovoltaic applications. Appl. Surf. Sci. 2009, 255, 7028-7035. [CrossRef]

42. Li, S.F.; Bauer, M.R.; Menéndez, J.; Kouvetakis, J. Scaling law for the compositional dependence of Raman frequencies in SnGe and GeSi alloys. Appl. Phys. Lett. 2004, 84, 867-869. [CrossRef]

43. Rojas-López, M.; Navarro-Contreras, H.; Desjardins, P.; Gurdal, O.; Taylor, N.; Carlsson, J.R.A.; Greene, J.E. Raman scattering from fully strained $\mathrm{Ge}_{1-\mathrm{x}} \mathrm{Sn}_{\mathrm{x}}(\mathrm{x}<0.22)$ alloys grown on $\mathrm{Ge}(001) 2 \times 1$ by low-temperature molecular beam epitaxy. J. Appl. Phys. 1998, 84, 2219-2223. [CrossRef]

44. Su, S.; Wang, W.; Cheng, B.; Hu, W.; Zhang, G.; Xue, C.; Zuo, Y.; Wang, Q. The contributions of composition and strain to the phonon shift in $\mathrm{Ge}_{1-\mathrm{x}} \mathrm{Sn}_{\mathrm{x}}$ alloys. Solid State Commun. 2011, 151, 647-650. [CrossRef]

45. Nakatsuka, O.; Mochizuki, K.; Shimura, Y.; Yamaha, T.; Zaima, S. Low temperature formation of $\mathrm{Si}_{1-x-y} \mathrm{Ge}_{\mathrm{x}} \mathrm{Sn}_{\mathrm{y}}$ on insulator structures by using solid-phase mixing of $\mathrm{Ge}_{1-\mathrm{z}} \mathrm{Sn}_{\mathrm{z}} / \mathrm{Si}$ on insulator substrates. Thin Solid Films 2012, 520, 3288-3292. [CrossRef]

46. Okugawa, M.; Nakamura, R.; Ishimaru, M.; Yasuda, H.; Numakura, H. Thermal crystallization of sputter-deposited amorphous Ge films: Competition of diamond cubic and hexagonal phases. AIP Adv. 2016, 6, 125035. [CrossRef]

(C) 2018 by the authors. Licensee MDPI, Basel, Switzerland. This article is an open access article distributed under the terms and conditions of the Creative Commons Attribution (CC BY) license (http:/ / creativecommons.org/licenses/by/4.0/). 